\title{
on yourfeet
}

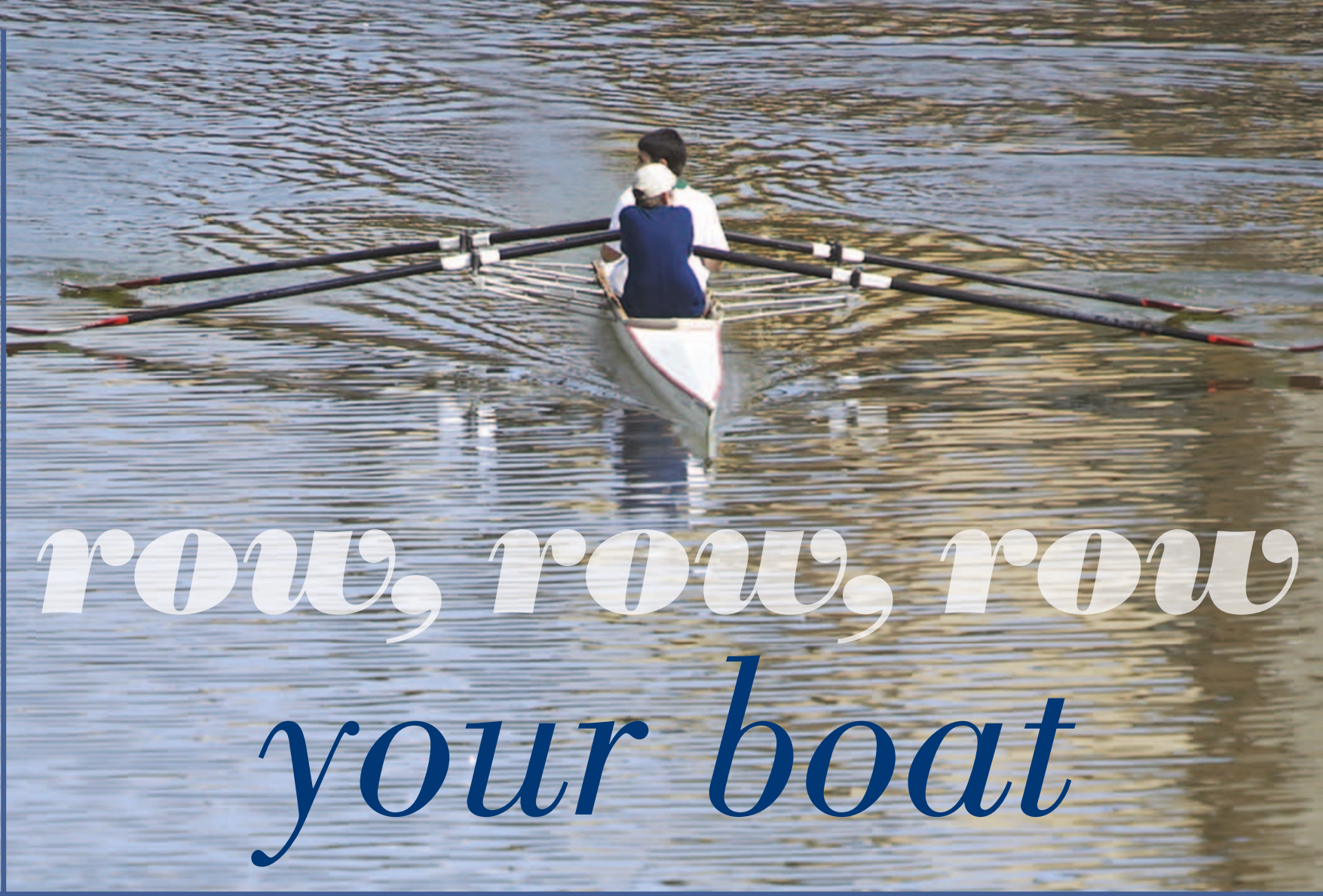

Ever wished your rowing machine was

whooshing through sparkly blue water rather than rooted to the floor? Sarah Hicks took the plunge, and caused a splash.

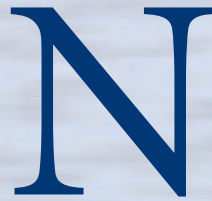
ow, I am not one for the lonely treadmill or exercise bike, and am not motivated by the calorie counter slowly ticking from 1 to 500 as I sweat it out with 30 others in silence. I needed to find a sport that let me be out in the open, did not require a massive amount of coordination, and could be done all year round. With this in mind I explored my options and discovered the sport of kings - not horse racing, but rowing.

Rowing has been popular in the UK for centuries. Despite having aristocratic origins, recreational and competitive rowing is now accessible to us all. Rowing clubs are dotted throughout the country, and you are sure to be able to find one near you, provided there is water flowing! An established team sport, rowing lets you improve your cardi- ovascular fitness and at the same time meet new people.

A sport for all ages, there are two types of rowing: sculling and sweep oar. Simply put, sculling is where you have two oars, and sweep is where you row with only one oar, which is larger and longer. Most clubs row across different levels of expertise, have mixed social crews and male and female only boats.

Rowing may conjure up visions of early morning slogs up and down a lonely river, with the aim of cutting a fine form on race day. Now before you swiftly turn the page vowing never to row - since taking up rowing I have discovered that you don't need to do the early mornings, nor do you have to compete! Rowing can be competitive, but it is also very social. The community that surrounds it is very lively - living by the motto 'row hard play hard'.
When I began rowing at my local club there were a couple of near collisions and the occasional capsize, but this was all part of the fun. I was soon looking forward to my twiceweekly visits after work, even the unexpected swims! I have also found myself to be part of a thriving social circle.

I intended to row to keep fit, but as I have met more people and started having a paddle in crews I am beginning to think about rowing as a more permanent, long term part of my life. I would definitely recommend rowing as an adventurous and invigorating alternative to the gym. Who knows - I may even don some lycra and start competing!

\section{Useful websites}

For more information about rowing, go to the UK Amateur Rowing Association website:

http://www.oara-rowing.org. This site provides a great overview of rowing, and gives you contact details of clubs nearest to you.

www.oara-rowing.org

www.trymysport.co.uk/rowing

www.oceanrowing.com 